\title{
Contrasting sex-dependent adaptations to synaptic physiology and membrane properties of prefrontal cortex interneuron subtypes in a mouse model of binge drinking
}

\author{
Max E. Joffe ${ }^{\dagger, a, b, c}$, Danny G. Winder ${ }^{\star}, a, c, d$, P. Jeffrey Conn ${ }^{\star}, a, b, c$ \\ a.Department of Pharmacology, Vanderbilt University, Nashville, TN, 37232, USA. \\ b.Vanderbilt Center for Neuroscience Drug Discovery, Nashville, TN, 37232, USA \\ c.Vanderbilt Center for Addiction Research, Nashville, TN, 37232, USA \\ d.Department of Molecular Physiology and Biophysics, Vanderbilt University, Nashville, TN, \\ 37232, USA
}

\section{Abstract}

Alcohol use disorder (AUD) affects all sexes, however women who develop AUD may be particularly susceptible to cravings and other components of the disease. While many brain regions are involved in AUD etiology, proper prefrontal cortex (PFC) function is particularly important for top-down craving management and the moderation of drinking behaviors. Essential regulation of PFC output is provided by local inhibitory interneurons, yet how drinking affects interneuron physiology remains poorly understood, particularly in female individuals. To address this gap, we generated fluorescent reporter transgenic mice to label the two major classes of interneuron in deep layer prelimbic PFC, based on expression of parvalbumin (PV-IN) or somatostatin (SST-IN). We then interrogated PV-IN and SST-IN membrane and synaptic physiology in a rodent model of binge drinking. Beginning in late adolescence, mice received 3-4 weeks of intermittent access (IA) ethanol. We prepared acute brain slices one day after the last drinking session. PV-INs but not SST-INs from IA ethanol mice displayed increased excitability relative to controls, regardless of sex. On the contrary, synaptic adaptations to PV-INs differed based on sex. While drinking decreased excitatory synaptic strength onto PV-INs from female mice, PV-INs from IA ethanol male mice exhibited potentiated excitatory transmission relative to controls. In contrast, decreased synaptic strength onto SST-INs was observed following IA ethanol in all groups of mice. Together, these findings illustrate novel sex differences in drinking-related

\footnotetext{
${ }^{\dagger}$ Correspondence to: Max E. Joffe, Ph.D., Postdoctoral Fellow, Vanderbilt University, 12475E MRB4, Nashville, TN 37232-0697, max.joffe@vanderbilt.edu Twitter: @mejoffe.

Equal contribution

Author Contributions

Conceptualization, M.E.J; Investigation, M.E.J.; Supervision, D.G.W. and P.J.C.; Writing - Original Draft, M.E.J.; Writing - Review \& Editing - all authors; Funding Acquisition, M.E.J. and P.J.C.

Publisher's Disclaimer: This is a PDF file of an unedited manuscript that has been accepted for publication. As a service to our customers we are providing this early version of the manuscript. The manuscript will undergo copyediting, typesetting, and review of the resulting proof before it is published in its final form. Please note that during the production process errors may be discovered which could affect the content, and all legal disclaimers that apply to the journal pertain.

Declaration of Interests

P.J.C. receives research support from Lundbeck Pharmaceuticals and Boehringer Ingelheim P.J.C. is an inventor on multiple patents for allosteric modulators of metabotropic glutamate receptors. M.E.J. and D.G.W. declare no potential conflicts of interest.
} 
PFC pathophysiology. Discovering means to restore PV-IN and SST-IN dysfunction following extended drinking provides opportunities for developing new treatments for all AUD patients.

\section{Graphical Abstract}
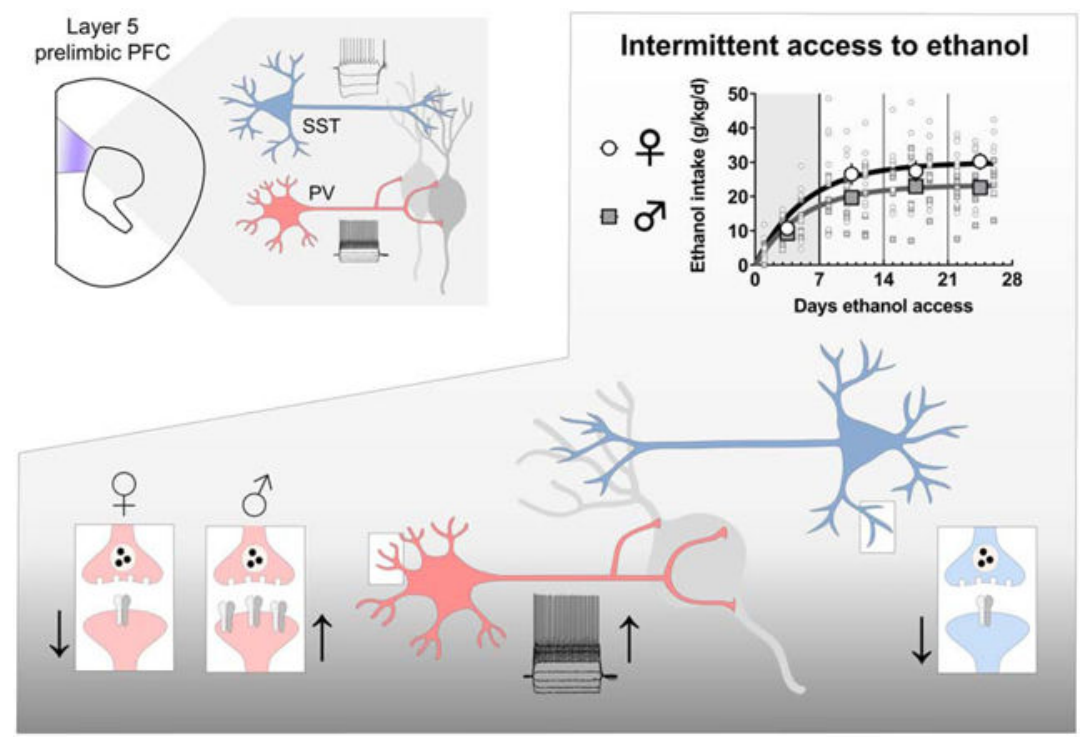

\section{Keywords}

alcohol; prefrontal cortex; sex differences; synaptic physiology; parvalbumin; somatostatin

\section{Introduction}

Alcohol use disorder (AUD) affects all groups of people (Hasin et al., 2007), however the prevalence of alcohol abuse among women is increasing (Grant et al., 2017) and several concerning findings indicate that women are at high risk for detrimental outcomes. Women are disproportionately affected by consequences of acute intoxication (Gross and Billingham, 1998) and are particularly sensitive to peripheral diseases and cognitive disturbances stemming from chronic alcohol consumption (Nixon et al., 1995; UrbanoMarquez et al., 1995). Furthermore, the prevalence of binge drinking is increasing among women (Grucza et al., 2018) and women who develop AUD progress rapidly through disease milestones (Diehl et al., 2007; Randall et al., 1999), suggesting sex differences regulate the top-down control over drinking. These sex differences are likely mediated, in part, by the medial prefrontal cortex (PFC), a region whose dysfunction is linked with deficits in the ability to control alcohol cravings in AUD patients and animal models (Abernathy et al., 2010; George and Koob, 2010). In addition to this overall relationship, binge drinkers and AUD patients display sex differences in PFC structure (Medina et al., 2008; Squeglia et al., 2012), and women with AUD display opposite patterns of PFC activation during working memory tasks relative to men (Caldwell et al., 2005). Together, these findings provide compelling rationale for continued mechanistic research to understand sex differences in PFC pathophysiology in AUD-like disease models. 
Preclinical studies designed to model alcohol-induced changes to PFC function have largely utilized the chronic intermittent ethanol (CIE) exposure paradigm, an animal model of dependence. Using CIE and other chronic treatment models, several labs have described dependence-related changes in PFC physiology to be generally characterized by reduced inhibition and enhanced excitatory synaptic activity (Centanni et al., 2017; Hu et al., 2015; Pava and Woodward, 2014; Pleil et al., 2015; Varodayan et al., 2018). In addition, changes in NMDA receptor function (Hu et al., 2015; Kroener et al., 2012), intrinsic properties (Hu et al., 2015), and PFC network activity (Kroener et al., 2012; Woodward and Pava, 2009), have all been shown to occur as a consequence of long-term alcohol exposure and withdrawal. While the literature clearly demonstrates that PFC pathophysiology develops during dependence, deficits in PFC function are also associated with maladaptive changes in voluntary drinking (Haun et al., 2018; Klenowski et al., 2016; Radke et al., 2017b; Salling et al., 2018; Seif et al., 2013; Siciliano et al., 2019). Moreover, mounting evidence suggests that PFC interneurons may be particularly important for regulating volitional alcoholseeking. For example, genetic disruption of synaptic transmission on forebrain interneurons, but not projection neurons, decreases drinking in mice (Radke et al., 2017a), and early abstinence from voluntary ethanol specifically increases Fos expression in PFC interneurons (George et al., 2012). While these exciting findings suggest that PFC inhibitory microcircuits instruct drinking moderation, much remains to be learned about the specific cell types and synapses underlying these processes.

A major source of PFC output arises from deep layer pyramidal cells. While pyramidal cells comprise approximately $80 \%$ of the neurons in PFC, the remaining interneurons are essential in coordinating the output from the structure (Ferguson and Gao, 2018). Deep layer PFC contains two general classes of local inhibitory interneurons that are readily divided by their form, function, and genetics. The synapses of one class appose the cell bodies of neighboring pyramidal cells, where they exert powerful feedforward inhibition to synchronize PFC network activity and output (Atallah et al., 2012; Sohal et al., 2009). These interneurons, also known as "basket cells", have unique intrinsic properties that can be used to functionally demarcate them from regular-spiking pyramidal cells or low-threshold spiking interneurons (Miyamae et al., 2017; Rotaru et al., 2011). Previous studies using this approach have revealed that acute ethanol (Woodward and Pava, 2009) and CIE (TranthamDavidson et al., 2014; Trantham-Davidson et al., 2017) each disrupt PFC fast-spiking interneuron function. These fast-spiking interneurons exclusively express the $\mathrm{Ca}^{2+}$-binding protein parvalbumin (PV). Transgenic mouse lines have been engineered to express fluorescent markers and manipulate protein expression under the control of the PV promotor (Miyamae et al., 2017; Taniguchi et al., 2011), enabling the means to selectively manipulate the physiology of PV-expressing interneurons (PV-INs). Recent studies have leveraged these tools to reveal that $\mathrm{GABA}_{\mathrm{A}}$ receptor subunit ablation from PV-INs increases binge drinking in male mice, but not female mice (Melon et al., 2018), supporting the hypothesis that this interneuron subtype regulates sex differences in top-down control. In addition to PV-INs, the second class of deep layer PFC interneurons expresses the neuropeptide somatostatin (SSTINs). Relatively little is known about how ethanol regulates SST-IN function, partly because these neurons are more difficult to functionally separate from pyramidal cells without genetic labeling tools. In general, SST-INs project to the superficial dendrites of neighboring 
pyramidal cells to filter synaptic information as it flows towards the cell body. SST-INs are therefore critical for processing long-range transmission and interactions with subcortical areas (Abbas et al., 2018). In sum, PV-INs and SST-INs serve essential, complimentary functions in mediating feedforward and feedback inhibition in the PFC.

Female rodents exhibit higher levels of voluntary alcohol consumption than male counterparts (Becker and Lopez, 2004; Hwa et al., 2011; Jury et al., 2017; McCall et al., 2013). The behavioral findings are striking and consistent across laboratories, but the mechanisms through which PFC dysregulation contributes to this phenomenon remain unclear. Most previous studies examining PFC dysfunction were conducted in male rodents and interneurons were solely classified based on membrane properties. In addition, most studies examining PFC interneurons were performed following non-contingent exposure, leaving us with a relatively limited understanding of how PFC inhibitory microcircuits adapt following long-term volitional drinking. Based on this, we utilized transgenic fluorescent reporter mice to investigate sex differences in PFC PV-IN and SST-IN physiology in a binge drinking model. Binge drinking can impair cognition, predispose individuals to risky decision-making, and lead to the escalation of maladaptive drinking behaviors. We therefore focused on interneurons within the prelimbic subregion of the PFC due to its roles in modulating executive functions and alcohol-seeking (Abernathy et al., 2010), as well as to facilitate comparisons with previous studies (Hughes et al., 2019; Trantham-Davidson et al., 2014; Trantham-Davidson et al., 2017). After intermittent access (IA) ethanol exposure, we observed increased excitability of PV-INs, but not SST-INs, of all mice. With regards to synaptic physiology, however, IA ethanol generated diametrically opposing changes to PVINs across sexes. By contrast, excitatory synaptic strength onto SST-INs was decreased in all groups of mice after IA ethanol. Collectively, these findings highlight striking and contrasting adaptations to cortical interneuron synaptic physiology induced by long-term voluntary drinking.

\section{Material and Methods}

\subsection{Mice}

Mice were bred and housed in a controlled environment on a standard 12-hour light cycle (on at 6:00 am). Transgenic mice expressing tdTomato fluorescent protein in PFC interneurons were generated by crossing female PV-Cre mice (Jackson Laboratories, Stock No: 017320) or SST-IRES-Cre mice (Jackson Laboratories, Stock No: 028864) with male Rosa26-loxP-STOP-loxP-CAG-tdTomato “Ai9” mice (Jackson Laboratories, Stock No: 007909). All breeding strains were congenic on a C57BL/6J genetic background. Only female PV-Cre mice were used for breeding to mitigate PV-Cre driven recombination that can occur in sperm. All breeding mice were homozygous for the respective transgene, generating heterozygous PV-tdTomato and SST-tdTomato mice suitable for experimentation. Mice were defined as female or male by their external genitalia and the current studies are limited by this definition. Male and female mice were always housed in the same rooms in clear polysulfone individually ventilated cages (NexGen Mouse 900, Allentown Incorporated). Air entered each cage directly through the housing racks after passing through a high efficiency particulate air filter system (Ecoflo Supply, Allentown 
Incorporated). Cages were maintained at positive pressure while docked on the rack system. Mice were housed in groups of 2-5 for initial sex comparison studies and sacrificed at 7-8 weeks of age (Figures 2 and 3). Mice were housed individually to accurately measure consumption during IA ethanol and sacrificed at 10-12 weeks of age (Figures 4-7).

\subsection{Intermittent access (IA) to ethanol}

Mice provided with IA ethanol drink more per day than continuous access controls (Hwa et al., 2011), and the C57BL/6J strain consumes more ethanol than other strains (Belknap et al., 1993; Boyce-Rustay et al., 2008; Rodgers and Mc, 1962). For these reasons, we selected the IA schedule in C57BL/6J mice as a robust rodent model of binge drinking. IA ethanol began during late adolescence (6-7 weeks). For alternating 24-hour periods, mice were provided with free access to ethanol in their home cages (Figure 1A). Water and food were always provided ad libitum. Mice were individually housed 3-7 days prior to IA ethanol initiation and remained so until sacrifice. Ethanol was diluted from $95 \%$ undenatured ethyl alcohol (Decon Labs, Incorporated) in reverse-osmosis water. Water and ethanol were placed in 50-mL Falcon tubes capped with rubber stoppers (Fisherbrand 14-135H, Fisher Scientific) and open tip straight tubes (OT100, Ancare). Tubes were weighed before and after each 24hour session and the average liquid drip $(0.2 \mathrm{~g})$ was subtracted from all values. Ethanol was provided 3-4 hours prior to the dark cycle and removed one day later. For the first week of access, the concentration of ethanol was slowly ramped up $(3,6,10 \%)$ to $20 \%$ ethanol, which was used for the duration of the study. The amount of ethanol and water consumed per day was measured by weight after each drinking session. As expected, female mice drank more ethanol than matched male mice (Figure 1B and 1C). We observed no sex differences in preference for ethanol over water across the IA access procedure (Figure 1D and 1E).

\subsection{Electrophysiology}

After 3-4 weeks of 20\% ethanol intake, we assessed physiological changes to PV-IN and SST-IN physiology. Mice were sacrificed 16-20 hours after the last session, a time linked to increased PFC interneuron activity (George et al., 2012). Acute prelimbic PFC slices were prepared for whole-cell patch-clamp physiology as described (Di Menna et al., 2018). In brief, mice were anesthetized with isoflurane and decapitated. Brains were rapidly removed without perfusion and submerged in $N$-methyl-D-glucamine solution. Immediately after preparation, coronal slices $(300 \mu \mathrm{M})$ recovered for 10 minutes in warm $\left(30-32^{\circ} \mathrm{C}\right) \mathrm{N}$ methyl-D-glucamine solution (in mM): $93 \mathrm{~N}$-methyl-D-glucamine, $20 \mathrm{HEPES}, 2.5 \mathrm{KCl}, 0.5$ $\mathrm{CaCl} 2,10 \mathrm{MgCl}$, 1.2 NaH2PO4, 25 glucose, 5 Na-ascorbate, and 3 Na-pyruvate. Slices were then maintained in room-temperature $\left(22-24{ }^{\circ} \mathrm{C}\right)$ for 1 hour in artificia 1 cerebrospinal fluid, containing (in mM): $119 \mathrm{NaCl}, 2.5 \mathrm{KCl}, 2.5 \mathrm{CaCl}_{2}, 1.3 \mathrm{MgCl}_{2}, 1 \mathrm{NaH}_{2} \mathrm{PO}_{4}, 11$ glucose, and $26 \mathrm{NaHCO}_{3}$. Membrane properties were assessed in current clamp configuration using a potassium-based internal solution (in $\mathrm{mM}$ ): $125 \mathrm{~K}$-gluconate, $4 \mathrm{NaCl}$, 10 HEPES, 4 MgATP, 0.3 NaGTP, 10 Tris-phosphocreatine. Cells were dialyzed with internal solution for 5 minutes, after which a series of 20, 1-sec current injections were applied. Injections began at $-150 \mathrm{pA}$, were incremented at $25 \mathrm{pA}$, and ended at $+300 \mathrm{pA}$. $\mathrm{R}_{\mathrm{m}}$ was calculated as the slope of the membrane potential hyperpolarization divided by the injected current. Sag ratio was evaluated based on the resting membrane potential $\left(\mathrm{V}_{\mathrm{m}}\right)$ and 
hyperpolarization in response to $-150 \mathrm{pA}$ current injection. Sag ratio was calculated as the difference between the peak hyperpolarization and the steady-state, normalized to the steady-state (Joffe et al., 2019). Medium afterhyperpolarization (mAHP) was determined as the magnitude of the decrease in membrane potential during the 0.5 -sec period after a current injection resulted in $>20$ action potentials (generally 200-300 pA for PV-INs and $100-200 \mathrm{pA}$ for SST-INs). Cells were then switched to voltage clamp configuration, and spontaneous excitatory synaptic transmission was collected over 2 minutes. Interneurons were clamped at $-80 \mathrm{mV}$, near the chloride reversal potential, to electrically isolate excitatory postsynaptic currents (EPSCs). Spontaneous excitatory postsynaptic currents (sEPSCs) were detected with templates specific for each interneuron subtype. EPSCs and sEPSCs were completely blocked by the AMPA receptor antagonist NBQX (Figure S1). Finally, in some cells, the paired-pulse ratio (PPR) of evoked EPSCs was assessed using local electrical stimulation (5-50 $\mu \mathrm{A}, 0.1 \mathrm{~ms})$ of superficial layer 5 at $0.2 \mathrm{~Hz}$. Stimulation intensity was adjusted while delivering single pulses to evoke EPSCs with a range of 50-400 pA. Paired pulses were then interleaved at each intersimulus interval $(25-400 \mathrm{~ms})$. For each interval 6-7 traces were averaged to determine PPR. We routinely collected 2-3 cells per slice, including cases where membrane properties and sEPSCs were evaluated after PPR stimuli were delivered to a previous cell. Slice treatment and data collection protocols, including PPR stimuli, were identical across sexes and treatment conditions. Experiments for each genotype were conducted across 2 separate cohorts and similar trends were observed in each cohort. Sexes and treatment conditions were always controlled with littermates. For each cohort, recordings were performed over a 2-week period and we counterbalanced sexes/conditions by recording from 2 different groups most days.

\subsection{Interneuron classification}

Neurons were initially selected by tdTomato fluorescence. All PV-tdTomato neurons displayed functional characteristics consistent with fast-spiking interneurons and were included in experiments. Within the deep layers of the PFC, PV-expressing neurons exclusively display the physiological and anatomical characteristics of basket cells (Miyamae et al., 2017; Rotaru et al., 2011). While most SST-tdTomato neurons exhibited low-threshold firing consistent with Martinotti cells, approximately one-fourth displayed irregular or fast-spiking-like properties. SST-tdTomato neurons with low $\mathrm{R}_{\mathrm{m}}(<150 \mathrm{M} \Omega)$, hyperpolarized $\mathrm{V}_{\mathrm{m}}(<-75 \mathrm{mV})$, and high rheobase $(>100 \mathrm{pA})$ were immediately discarded, as they represent ectopic tdTomato expression stemming from transient SST expression during development (Hu et al., 2013), or non-Martinotti type SST-INs (Nigro et al., 2018).

\subsection{Statistics}

The number of cells or mice is denoted by " $\mathrm{n}$ " and/or "N" respectively, in each figure legend. Data are generally presented as mean \pm standard error or as box plots displaying median, interquartile range, and range. Analyses were performed in GraphPad Prism. Twotailed Mann Whitney U test, non-linear and linear least squares best-fit regression, and twoway ANOVA were used as appropriate. Where significant ( $a$ : 0.05) main effects of sex, or sex-IA ethanol interactions were observed, we used Sidak post-hoc comparisons to assess specific differences. For current-evoked spiking and paired-pulse ratio experiments, threeway ANOVA was used for initial analyses and a subsequent two-way ANOVA was used 
when interactions involving both sex and IA ethanol were observed. The F test to compare variances was used to analyze all data in Figures 1, 2, and 3. All statistical findings are displayed in the figures or figure legends.

\section{Results}

\subsection{Basal physiology of PFC PV-INs in female mice and male mice}

To assess whether PFC fast-spiking interneurons display sex differences in intrinsic and synaptic physiology, we generated mice expressing tdTomato in PV-expressing neurons (Figure 2A and 2B). Using whole-cell patch-clamp techniques we validated that $\mathrm{PV}(+)$ cells represent fast-spiking interneurons in layer 5 prelimbic PFC. Indeed, $\mathrm{PV}(+)$ cells display the hallmark characteristics of fast-spiking interneurons (Connors and Gutnick, 1990; Kawaguchi, 1993; Markram et al., 2004; McCormick et al., 1985), including high firing frequency and minimal spike-firing adaptation and hyperpolarization sag (Figure 2B-2F). PV-IN intrinsic properties were comparable between female and male mice, however PV-INs from male mice exhibited a smaller medium afterhyperpolarization (mAHP) than those from female mice (Figure 2G). Measurements of basal excitatory synaptic strength were also similar across sexes (Figure 2H and 2I), but the variance of PV-IN sEPSC frequency was greater in female mice in this cohort (Figure 2I).

\subsection{Basal physiology of PFC SST-INs in female mice and male mice}

To assess the intrinsic and synaptic physiology of PFC low-threshold spiking interneurons, we generated mice expressing tdTomato under control of the SST promotor (Figure 3A and 3B). In layer 5 PFC, most SST(+) cells represent low-threshold spiking interneurons, however some neurons displayed fast-spiking-like phenotypes and were immediately relinquished. Low-threshold spiking SST(+) cells display several characteristics of Martinotti cells (Nigro et al., 2018; Tremblay et al., 2016) including high $\mathrm{R}_{\mathrm{m}}$, depolarized $\mathrm{V}_{\mathrm{m}}$, low rheobase, and firing upon rebound from hyperpolarization (Figure 3B). SST-IN intrinsic properties and measurements of basal synaptic physiology were all comparable across sexes (Figure 3C-3I).

\subsection{Increased PV-IN excitability and afterhyperpolarization following IA ethanol}

Across most rodent strains, females voluntarily consume more ethanol than males. This phenotype has been observed across many laboratories (Becker and Lopez, 2004; Hwa et al., 2011; Jury et al., 2017; McCall et al., 2013; Priddy et al., 2017), but the etiology underlying the sex difference remains incompletely understood. To model high levels of volitional alcohol drinking, we implemented an intermittent access (IA) schedule, where mice were provided with alternating days of ethanol availability in their home cages. Female mice drank more than males (Figure 1), and we then assessed intrinsic properties of PFC PV-INs and SST-INs at one-day abstinence from IA ethanol. We observed minimal effects of IA ethanol treatment on resting membrane potential, hyperpolarization sag, or $\mathrm{R}_{\mathrm{m}}$ in either interneuron subtype in either sex (Figure S2 and Figure 4A and 4B). In contrast, PV-INs from IA ethanol mice exhibited increased spiking across a series of current injections (Figure 4C and 4D). In addition, many neuron types display mAHP, a brief ( 100-ms to 2sec) hyperpolarization following trains of action potentials. mAHP is generally mediated by 
voltage- and/or calcium-gated potassium channels and serves a feedback mechanism to limit continuous neural activity. PV-INs from all IA ethanol mice displayed greater mAHP than matched controls (Figure 4E and 4F). Together, these data indicate that PV-INs are hyperexcitable following IA ethanol and susceptible to enhanced feedback to limit their ongoing activity. We next examined membrane physiology of SST-INs. SST-IN $\mathrm{R}_{\mathrm{m}}$ was comparable across control and IA ethanol groups (Figure 5A and 5B), and, unlike PV-INs, SST-IN spike-firing was not affected by IA ethanol (Figure 5C and 5D). Interestingly, however, SST-INs from male but not female IA ethanol mice also displayed enhanced mAHP (Figure 5E and 5F). Overall, these intrinsic physiology adaptations suggest that IA ethanol alters the processes through which interneurons respond to synaptic input and alter PFC microcircuit function. We therefore aimed to better understand how binge drinking might modify excitatory input onto PFC PV-INs and SST-INs and investigated synaptic properties from controls and IA ethanol-exposed mice.

\subsection{Opposing changes to synaptic strength onto PFC PV-INs after IA ethanol in female and male mice}

PFC interneurons generally display low levels of basal activity in vivo. Instead, long-range excitatory afferents dynamically recruit PV-IN and SST-IN activity to shape local networks of PFC pyramidal cells through feedforward and feedback inhibition. Thus, assessing how IA ethanol alters the synaptic strength of excitatory synapses onto PFC interneurons is essential to place the observed membrane physiology changes within a holistic context. We first analyzed the amplitude and frequency of sEPSCs to assess quantal size and content of glutamate synapses onto PV-INs (Figure 6A). In female IA ethanol mice, we observed a decrease in sEPSC amplitude relative to controls (Figure 6B, left) suggesting PV-INs in female mice display reduced AMPA receptor function following IA ethanol. Moreover, PVINs from female IA ethanol mice displayed decreased sEPSC frequency (Figure 6B, right), suggesting fewer detectable synapses and/or decreased presynaptic glutamate release probability. To address these two possibilities, we next used electrical stimulation to evaluate the paired-pulse ratio (PPR), which is most often modulated by changes in neurotransmitter release probability. We observed no difference in PPR (Figure 6C and 6D), suggesting changes in presynaptic glutamate release do not play a major role in these adaptations following IA ethanol. In PV-INs of female mice, the overall changes are most consistent with attenuated postsynaptic AMPA receptor function and fewer detectable synapses. Opposing results were obtained in PV-INs from male mice. IA ethanol increased both sEPSC amplitude and frequency (Figure 6A and 6B) without affecting PPR (Figure 6C and 6D), suggesting enhanced function of postsynaptic AMPA receptors and an increase in the number of detectable excitatory synapses after IA ethanol exposure. While we observed likely postsynaptic changes in both groups, these striking findings indicate that the excitatory synapses onto PFC PV-INs undergo diametrically opposed changes in female and male mice. These synaptic adaptations are expected to attenuate and facilitate PV-IN recruitment by excitatory drive in female and male mice with a history of IA ethanol respectively. 


\subsection{Diminished synaptic strength onto PFC SST-INs after IA ethanol}

As with PV-INs, we evaluated changes to excitatory synaptic transmission onto SST-INs in control mice and those exposed to IA ethanol. In female mice, one-day abstinence from IA ethanol was associated with decreased excitatory synaptic strength (Figure 7A), as evidenced by reductions in both sEPSC amplitude and frequency (Figure 7B). The PPR of evoked EPSCs was not different between the control and IA ethanol groups (Figure 7C and 7D), suggesting these changes in excitatory transmission occurred through postsynaptic reduction in AMPA receptor function and the number of detectable synapses. We observed similar changes in male mice. IA ethanol produced an attenuation of sEPSC amplitude and frequency in SST-INs of male mice (Figure 7A and 7B). Surprisingly, we observed decreased PPR across multiple interstimulus intervals in these cells from the IA ethanol group (Figure 7C and 7D). Nonetheless, the collective dataset suggests that IA ethanol exposure attenuates excitatory transmission overall onto SST-INs in all groups of mice.

\subsection{Interindividual variation}

IA ethanol and other volitional drinking models provide straightforward opportunities to assess whether physiological adaptations may relate to ethanol exposure. To begin to address potential relationships, we performed correlational analyses to test whether PFC physiology is associated with ethanol intake. For each subject exposed to IA ethanol, we averaged each physiological parameter and assessed potential relationships with ethanol intake during the last week of exposure. Significant linear correlations were not observed between either $\mathrm{R}_{\mathrm{m}}$ or mAHP and ethanol intake in either ex in interneuron subpopulation (Figure S3). Similarly, neither sEPSC amplitude nor frequency displayed a significant correlation with ethanol intake in PV-INs or SST-INs from female mice or male mice (Figure S4).

\section{Discussion}

The PFC is essential for top-down moderation of drinking (Abernathy et al., 2010; George and Koob, 2010). The preclinical literature has primarily focused on how ethanol alters the function of PFC pyramidal cells, the principal neurons that convey information from the PFC to subcortical structures. Nonetheless, PFC output is dynamically regulated by local interneurons, so we sought to investigate physiological adaptations occurring on those discrete cell types following ethanol exposure. We functionally interrogated two genetically defined subtypes of PFC interneurons in a binge drinking model. PV-INs, and not SST-INs, were more excitable in IA ethanol mice of all sexes. In addition, IA ethanol enhanced mAHP in all PV-INs and also in SST-INs from male mice. With regards to synaptic physiology, IA ethanol induced disparate sex-dependent adaptations to PV-INs - diminished excitatory drive in female mice and enhanced postsynaptic AMPA receptor function in male mice. In contrast, IA ethanol dampened excitatory synaptic strength onto SST-INs in all groups of mice. Together, these data indicate that altered excitatory synaptic drive onto PV-INs and SST-INs may contribute to PFC dysfunction in AUD.

The changes we observed to PV-IN and SST-IN intrinsic and synaptic physiology may or may not be related. While we observed a significant increase in mAHP following IA ethanol in PV-INs from all mice and from SST-INs from male mice. Following sustained 
depolarization, the mAHP limits neural activity and calcium mobilization within a postsynaptic cell. Therefore, the coincidental ethanol-induced increases in PV-IN mAHP and synaptic strength in male mice are consistent with a homeostatic response, i.e. increased mAHP might provide a feedback mechanism to mitigate excessive activation of PV-INs following synaptic stimulation. In PV-INs from female mice and SST-INs, by contrast, an IA ethanol-induced increase in mAHP might have facilitated spike timing-dependent long-term depression (Lu et al., 2007), thereby initiating an ethanol-induced reduction synaptic strength. In addition - or as an alternative - to these potential causal relationships, the coincidental changes to mAHP and synaptic strength might be manifested by the further separation of PV-INs into responsive and non-responsive subpopulations. One intriguing hypothesis is that IA ethanol specifically enhances mAHP and modulates synaptic strength in a specific subtype of PV-IN. In addition, cortical SST-INs can be stratified into subclasses based on intrinsic properties, connectivity, and protein expression (Tremblay et al., 2016), and some of these factors may confer susceptibility to alcohol-related pathophysiology.

Female mice drink more ethanol than male counterparts and the current findings reveal that PFC PV-INs undergo distinct adaptations based on sex. These results beg the question, do ethanol-induced adaptations to PV-INs contribute to sex differences in drinking behaviors? Substantial further research is needed to address this question. For one, it remains unclear how PFC PV-IN activity in vivo modulates drinking and other appetitive behaviors. Experiments designed to monitor and manipulate PV-IN activity during a variety of components of ethanol-seeking tasks will be important to fully understand how molecular changes to PV-IN physiology confer AUD-like adaptations. One overly simple and wildly speculative prediction is that feedforward drive onto PV-INs inhibits cortical circuits involved in drinking behaviors, such as the PFC projections to the nucleus accumbens (Seif et al., 2013) or periaqueductal gray (Siciliano et al., 2019). Were that the case, decreased excitatory transmission onto PV-INs could facilitate drinking in female mice, while enhanced drive onto PV-INs in male mice might confer some resilience. It is also tempting to speculate that sex differences in PV-IN synaptic adaptations might be related to the sex differences in habit formation following ethanol exposure (Barker et al., 2010). On the other hand, attenuated drive onto SST-INs might promote drinking in all groups of mice. In addition to providing top-down control over drinking, the PFC regulates a variety of cognitive processes with relevance for AUD. In particular, working memory and cognitive flexibility are regulated by PFC PV-INs (Murray et al., 2015) and SST-INs (Abbas et al., 2018). Based on this, we predict that interneuron dysfunction likely contributes to impairments in PFC-dependent cognitive processes observed in animal models of AUD (George et al., 2012; Salling et al., 2018; Trantham-Davidson et al., 2014; Vargas et al., 2014). In addition, it would be of interest to examine whether similar alterations in interneuron physiology occur in infralimbic, anterior cingulate, or orbitofrontal cortices and contribute to AUD-like behavioral adaptations. Further research, however, is needed to test these hypotheses and to examine potential sex differences in AUD-related cognitive disruptions.

IA ethanol also induced pronounced adaptations to the synaptic physiology of SST-INs. Unlike PV-INs, overall spontaneous synaptic strength decreased onto SST-INs in both female mice and in male mice. However, a subtle sex difference emerged as SST-INs from 
male mice displayed decreased PPR following IA ethanol. At face value, decreased PPR suggests increased presynaptic glutamate release probability and are not consistent with the concomitant reduction in sEPSC frequency. We offer two likely explanations for this discrepancy: (1) distinct sets of synapses may have been sampled during spontaneous and evoked EPSC recordings, as has been observed at excitatory synapses onto other cell types in the central nervous system (Ramirez and Kavalali, 2011); and (2) SST-IN PPR may be regulated by a postsynaptic feature, such as the activity-dependent polyamine sensitivity of AMPA receptors previously observed in cortical interneurons (Rozov and Burnashev, 1999). Future studies should therefore be conducted to interrogate AMPA receptor expression and stoichiometry in interneuron subpopulations. Furthermore, the discrepant changes to PPR and SEPSC frequency in male SST-INs highlight the need to investigate specific sources of glutamate onto those interneurons. The canonical function of SST-expressing Martinotti cells involves lateral feedback inhibition between neighboring pyramidal cells (Tremblay et al., 2016). SST-INs, however, also receive substantial glutamate from long-range afferents from brain regions known to be modulated by ethanol exposure, such as the basolateral amygdala (McGarry and Carter, 2016). An intriguing hypothesis for future studies is that IA ethanol may (1) alter a discrete long-range input onto SST-INs, or (2) induce contrasting changes across more than one source of glutamate. Finally, because our recordings did not contain picrotoxin, another possibility is that changes in local PFC inhibitory microcircuits could contribute to the changes in apparent glutamate release probability onto SST-INs. Clearly, this initial finding suggests that IA ethanol induces complex physiological adaptations to SST-IN circuit function and these phenomena merit substantial further examination.

The preclinical literature modeling PFC dysfunction has generally utilized male subjects and focused on adaptations to pyramidal cells. Studies describing PFC interneuron dysfunction have been more limited and exclusively examined the physiological ramifications of ethanol dependence or chronic intoxication. Trantham-Davidson et al. (Trantham-Davidson et al., 2014) assessed intrinsic properties of functionally identified fast-spiking interneurons (putative PV-INs) in male rats exposed to CIE. CIE generated differences in dopamine modulation of fast-spiking interneuron current-evoked firing, but baseline excitability parameters, including input-output firing curves and mAHP, were not reported. Another recent paper by Hughes et al. (Hughes et al., 2019) described several changes to the intrinsic properties of PFC interneurons in a rat model of chronic intoxication. Following ethanol exposure, Hughes et al. observed decreased fast-spiking interneuron excitability in all rats, while we detected increased PV-IN spiking in mice. Further, Hughes et al. observed ethanolinduced sex differences in current-evoked firing in putative Martinotti cells, while we noted minimal effects on SST-IN intrinsic physiology in either female mice or male mice. Several major technical differences are likely to explain these discrepancies. Hughes et al. delivered an intoxicating dose of ethanol $(\sim 250 \mathrm{mg} / \mathrm{dL})$ to rats on successive days, whereas mice in the current studies voluntarily drank on alternating nights to reach moderate blood ethanol concentrations ( $\sim 80 \mathrm{mg} / \mathrm{dL}$ reported in previous studies (Hwa et al., 2011; Salling et al., 2018)). In addition to methodological differences in slice preparation and interneuron classification, differences between the two studies might stem from means of ethanol delivery, overall intake, pattern of intake, and species. Each of these parameters merits 
further examination. We believe the diversity of preclinical AUD models is a beneficial feature of the research community; continued research across several models well help elucidate the core features of disease etiology. Future studies should continue to address sex as a biological variable and examine differences between drinking during adolescence and adulthood. Initiating ethanol exposure during a single developmental stage is one limitation of the present studies, as previous research has indicated that ethanol exposure can differentially affect the adolescent versus adult PFC (Barker et al., 2017; TranthamDavidson et al., 2014; Trantham-Davidson et al., 2017), potentially related to hormonal fluctuation during adolescence in all sexes. Thus, the pathophysiological adaptations observed here might not generalize to other ages of ethanol exposure. The present findings are also limited by a single timepoint soon after ethanol discontinuation. Nonetheless, to our knowledge, the present study represents the first characterization of PFC interneuron synaptic physiology following voluntary drinking. Future studies should be designed to address the development and recovery of PFC interneuron pathophysiology and related behavioral adaptations across multiple disease models.

Based on the current findings, one would expect for inhibitory transmission onto PFC pyramidal cells to be altered following chronic drinking and in models of alcohol dependence. In ostensible contrast to that hypothesis, previous research did not reveal differences in inhibitory transmission onto deep layer prelimbic PFC pyramidal cells during acute withdrawal from CIE (Pleil et al., 2015; Trantham-Davidson et al., 2014). During those experiments, however, GABAergic inhibitory postsynaptic currents (IPSCs) on pyramidal cells were collected with non-specific electrical stimulation or in a spontaneous manner. The present findings suggest that output from each interneuron subpopulation is likely altered following ethanol exposure, but coincidental adaptations might have obfuscated changes in non-specific IPSCs in previous work. Our findings suggest this possibility is particularly likely for male subjects, as we observed contrasting changes to synaptic strength onto PV-INs and SST-INs in male mice. Consistent with this hypothesis, Trantham-Davidson et al. (Trantham-Davidson et al., 2014) discovered that CIE disrupted the ability of D4 dopamine receptors to modulate IPSCs recorded from pyramidal cells. D4 receptors regulate PV-IN function in the PFC (Zhong and Yan, 2016) and hippocampus (Andersson et al., 2012) without affecting other types of interneurons, suggesting that PVINs mediated the CIE-induced changes to D4 signaling observed by Trantham-Davidson et al (2014). Future investigations targeting PFC inhibitory synapses with interneuron typespecific manipulations, in both female and male rodents, should improve our understanding of how alcohol exposure dysregulates PFC function and assist efforts to discover novel targets for the treatment of AUD.

Restoring normal synaptic physiology on PFC PV-INs and SST-INs following IA ethanol may provide avenues to mitigating behavioral disruptions relevant to AUD. A better understanding of the mechanisms regulating synaptic plasticity on cortical interneurons would be essential towards these endeavors. Calcium-permeable AMPA receptors and NMDA receptors represent two candidate molecules that might modulate synaptic strength onto PV-INs and SST-INs during or after IA ethanol. Future studies should therefore examine drinking-related changes in AMPA and NMDA receptor expression, stoichiometry, and signaling on cortical interneurons. In addition to ionotropic glutamate receptors, changes 
in fast glutamate transmission are often mediated by metabotropic glutamate (mGlu) receptors. Several previous findings suggest mGlu receptors may be involved in the PFC interneuron synaptic pathophysiology we observed after IA ethanol. Transcript and protein for mGlu receptor subtypes $1\left(\mathrm{mGlu}_{1}\right)$ and $5\left(\mathrm{mGlu}_{5}\right)$ are enriched in interneurons, and $\mathrm{mGlu}_{1}$ and $\mathrm{mGlu}_{5}$ have been implicated in forms of long-term potentiation specific to interneurons within the hippocampus (Le Duigou and Kullmann, 2011; Perez et al., 2001). Furthermore, $\mathrm{mGlu}_{5}$, but not $\mathrm{mGlu}_{1}$, gates long-term potentiation onto fast-spiking interneurons in the visual cortex (Sarihi et al., 2008), but these plasticity mechanisms have not, to our knowledge, been investigated in the PFC or other associative cortices. In addition to these plasticity mechanisms, pronounced sex differences in mGlu $_{1}$ and mGlu $_{5}$ signaling have been observed in the limbic system: estradiol regulates hippocampal inhibitory transmission through $\mathrm{mGlu}_{1}$, (Huang and Woolley, 2012), and sex hormones modulate mGlu $_{5}$-dependent synaptic plasticity in the nucleus accumbens (Gross et al., 2018; Peterson et al., 2015). Moreover, while preparing our revised manuscript, a new article described sexdependent changes to $\mathrm{mGlu}_{1 / 5}$ signaling in the bed nucleus of the stria terminalis following adolescent ethanol exposure (Kasten et al., 2020). Altogether, the breadth of preclinical literature raises the possibility that changes in PFC glutamate transmission during IA ethanol might recruit $\mathrm{mGlu}_{1}$ or $\mathrm{mGlu}_{5}$ signaling to modulate synaptic strength on PV-INs and SSTINs in a sex-dependent manner. Excitingly, small molecule modulators of mGlu ${ }_{1}$ and mGlu are efficacious in multiple preclinical AUD models (Joffe et al., 2018), providing further impetus for investigating how these signaling pathways may underlie disease etiology.

\section{Conclusion}

Interneurons arise from distinct progenitors and express distinct transcriptional programs, presenting opportunities to leverage biological idiosyncrasies for the targeted treatment of disease. Efficacious AUD treatments might one day be developed from cortical interneuron dysfunction initially observed in a preclinical disease model. The striking adaptations to synaptic physiology described here provide one potential starting place.

\section{Supplementary Material}

Refer to Web version on PubMed Central for supplementary material.

\section{Acknowledgements}

The authors thank members of the Conn and Winder labs for stimulating discussions. Research was supported by National Institutes of Health grants R01MH062646 and R37NS031373 (P.J.C.). M.E.J. was supported by National Institutes of Health grants K99AA027806 and a postdoctoral fellowship through the Pharmaceutical Research and Manufacturers of America Foundation.

\section{References}

Abbas AI, Sundiang MJM, Henoch B, Morton MP, Bolkan SS, Park AJ, Harris AZ, Kellendonk C, Gordon JA, 2018 Somatostatin Interneurons Facilitate Hippocampal-Prefrontal Synchrony and Prefrontal Spatial Encoding. Neuron 100, 926-939 e923. [PubMed: 30318409]

Abernathy K, Chandler LJ, Woodward JJ, 2010 Alcohol and the prefrontal cortex. Int Rev Neurobiol 91, 289-320. [PubMed: 20813246] 
Andersson R, Johnston A, Fisahn A, 2012 Dopamine D4 receptor activation increases hippocampal gamma oscillations by enhancing synchronization of fast-spiking interneurons. pLoS One 7, e40906. [PubMed: 22815864]

Atallah BV, Bruns W, Carandini M, Scanziani M, 2012 Parvalbumin-expressing interneurons linearly transform cortical responses to visual stimuli. Neuron 73, 159-170. [PubMed: 22243754]

Barker JM, Bryant KG, Osborne JI, Chandler LJ, 2017 Age and Sex Interact to Mediate the Effects of Intermittent, High-Dose Ethanol Exposure on Behavioral Flexibility. Front Pharmacol 8, 450. [PubMed: 28736526]

Barker JM, Torregrossa MM, Arnold AP, Taylor JR, 2010 Dissociation of genetic and hormonal influences on sex differences in alcoholism-related behaviors. J Neurosci 30, 9140-9144. [PubMed: 20610747]

Becker HC, Lopez MF, 2004 Increased ethanol drinking after repeated chronic ethanol exposure and withdrawal experience in C57BL/6 mice. Alcohol Clin Exp Res 28, 1829-1838. [PubMed: 15608599]

Belknap JK, Crabbe JC, Young ER, 1993 Voluntary consumption of ethanol in 15 inbred mouse strains. Psychopharmacology (Berl) 112, 503-510. [PubMed: 7871064]

Boyce-Rustay JM, Janos AL, Holmes A, 2008 Effects of chronic swim stress on EtOH-related behaviors in C57BL/6J, DBA/2J and BALB/cByJ mice. Behav Brain Res 186, 133-137. [PubMed: 17822784]

Caldwell LC, Schweinsburg AD, Nagel BJ, Barlett VC, Brown SA, Tapert SF, 2005 Gender and adolescent alcohol use disorders on BOLD (blood oxygen level dependent) response to spatial working memory. Alcohol Alcohol 40, 194-200. [PubMed: 15668210]

Centanni SW, Burnett EJ, Trantham-Davidson H, Chandler LJ, 2017 Loss of delta-GABAA receptormediated tonic currents in the adult prelimbic cortex following adolescent alcohol exposure. Addict Biol 22, 616-628. [PubMed: 26804056]

Connors BW, Gutnick MJ, 1990 Intrinsic firing patterns of diverse neocortical neurons. Trends Neurosci 13, 99-104. [PubMed: 1691879]

Di Menna L, Joffe ME, Iacovelli L, Orlando R, Lindsley CW, Mairesse J, Gressens P, Cannella M, Caraci F, Copani A, Bruno V, Battaglia G, Conn PJ, Nicoletti F, 2018 Functional partnership between mGlu3 and mGlu5 metabotropic glutamate receptors in the central nervous system. Neuropharmacology 128, 301-313. [PubMed: 29079293]

Diehl A, Croissant B, Batra A, Mundle G, Nakovics H, Mann K, 2007 Alcoholism in women: is it different in onset and outcome compared to men? Eur Arch Psychiatry Clin Neurosci 257, 344 351. [PubMed: 17629733]

Ferguson BR, Gao WJ, 2018 PV Interneurons: Critical Regulators of E/I Balance for Prefrontal Cortex-Dependent Behavior and Psychiatric Disorders. Front Neural Circuits 12, 37. [PubMed: 29867371]

George O, Koob GF, 2010 Individual differences in prefrontal cortex function and the transition from drug use to drug dependence. Neurosci Biobehav Rev 35, 232-247. [PubMed: 20493211]

George O, Sanders C, Freiling J, Grigoryan E, Vu S, Allen CD, Crawford E, Mandyam CD, Koob GF, 2012 Recruitment of medial prefrontal cortex neurons during alcohol withdrawal predicts cognitive impairment and excessive alcohol drinking. Proc Natl Acad Sci U S A 109, 1815618161. [PubMed: 23071333]

Grant BF, Chou SP, Saha TD, Pickering RP, Kerridge BT, Ruan WJ, Huang B, Jung J, Zhang H, Fan A, Hasin DS, 2017 Prevalence of 12-Month Alcohol Use, High-Risk Drinking, and DSM-IV Alcohol Use Disorder in the United States, 2001-2002 to 2012-2013: Results From the National Epidemiologic Survey on Alcohol and Related Conditions. JAMA Psychiatry 74, 911-923. [PubMed: 28793133]

Gross KS, Moore KM, Meisel RL, Mermelstein PG, 2018 mGluR5 Mediates DihydrotestosteroneInduced Nucleus Accumbens Structural Plasticity, but Not Conditioned Reward. Front Neurosci 12, 855. [PubMed: 30515075]

Gross WC, Billingham RE, 1998 Alcohol consumption and sexual victimization among college women. Psychol Rep 82, 80-82. [PubMed: 9520538] 
Grucza RA, Sher KJ, Kerr WC, Krauss MJ, Lui CK, McDowell YE, Hartz S, Virdi G, Bierut LJ, 2018 Trends in Adult Alcohol Use and Binge Drinking in the Early 21st-Century United States: A MetaAnalysis of 6 National Survey Series. Alcohol Clin Exp Res 42, 1939-1950. [PubMed: 30080258]

Hasin DS, Stinson FS, Ogburn E, Grant BF, 2007 Prevalence, correlates, disability, and comorbidity of DSM-IV alcohol abuse and dependence in the United States: results from the National Epidemiologic Survey on Alcohol and Related Conditions. Arch Gen Psychiatry 64, 830-842. [PubMed: 17606817]

Haun HL, Griffin WC, Lopez MF, Solomon MG, Mulholland PJ, Woodward JJ, McGinty JF, Ron D, Becker HC, 2018 Increasing Brain-Derived Neurotrophic Factor (BDNF) in medial prefrontal cortex selectively reduces excessive drinking in ethanol dependent mice. Neuropharmacology 140, 35-42. [PubMed: 30056122]

$\mathrm{Hu} \mathrm{H}$, Cavendish JZ, Agmon A, 2013 Not all that glitters is gold: off-target recombination in the somatostatin-IRES-Cre mouse line labels a subset of fast-spiking interneurons. Front Neural Circuits 7, 195. [PubMed: 24339803]

$\mathrm{Hu}$ W, Morris B, Carrasco A, Kroener S, 2015 Effects of acamprosate on attentional set-shifting and cellular function in the prefrontal cortex of chronic alcohol-exposed mice. Alcohol Clin Exp Res 39, 953-961. [PubMed: 25903298]

Huang GZ, Woolley CS, 2012 Estradiol acutely suppresses inhibition in the hippocampus through a sex-specific endocannabinoid and mGluR-dependent mechanism. Neuron 74, 801-808. [PubMed: 22681685]

Hughes BA, Crofton EJ, O'Buckley TK, Herman MA, Morrow AL, 2019 Chronic ethanol exposure alters prelimbic prefrontal cortical Fast-Spiking and Martinotti interneuron function with differential sex specificity in rat brain. Neuropharmacology 162, 107805. [PubMed: 31589884]

Hwa LS, Chu A, Levinson SA, Kayyali TM, DeBold JF, Miczek KA, 2011 Persistent escalation of alcohol drinking in C57BL/6J mice with intermittent access to 20\% ethanol. Alcohol Clin Exp Res 35, 1938-1947. [PubMed: 21631540]

Joffe ME, Centanni SW, Jaramillo AA, Winder DG, Conn PJ, 2018 Metabotropic Glutamate Receptors in Alcohol Use Disorder: Physiology, Plasticity, and Promising Pharmacotherapies. ACS Chem Neurosci.

Joffe ME, Santiago CI, Oliver KH, Maksymetz J, Harris NA, Engers JL, Lindsley CW, Winder DG, Conn PJ, 2019 mGlu2 and mGlu3 Negative Allosteric Modulators Divergently Enhance Thalamocortical Transmission and Exert Rapid Antidepressant-like Effects. Neuron.

Jury NJ, DiBerto JF, Kash TL, Holmes A, 2017 Sex differences in the behavioral sequelae of chronic ethanol exposure. Alcohol 58, 53-60. [PubMed: 27624846]

Kasten CR, Carzoli KL, Sharfman NM, Henderson T, Holmgren EB, Lerner MR, Miller MC, Wills TA, 2020 Adolescent alcohol exposure produces sex differences in negative affect-like behavior and group I mGluR BNST plasticity. Neuropsychopharmacology.

Kawaguchi Y, 1993 Groupings of nonpyramidal and pyramidal cells with specific physiological and morphological characteristics in rat frontal cortex. J Neurophysiol 69, 416-431. [PubMed: 8459275]

Klenowski PM, Fogarty MJ, Shariff M, Belmer A, Bellingham MC, Bartlett SE, 2016 Increased Synaptic Excitation and Abnormal Dendritic Structure of Prefrontal Cortex Layer V Pyramidal Neurons following Prolonged Binge-Like Consumption of Ethanol. eNeuro 3.

Kroener S, Mulholland PJ, New NN, Gass JT, Becker HC, Chandler LJ, 2012 Chronic alcohol exposure alters behavioral and synaptic plasticity of the rodent prefrontal cortex. PLoS One 7, e37541. [PubMed: 22666364]

Le Duigou C, Kullmann DM, 2011 Group I mGluR agonist-evoked long-term potentiation in hippocampal oriens interneurons. J Neurosci 31, 5777-5781. [PubMed: 21490219]

Lu JT, Li CY, Zhao JP, Poo MM, Zhang XH, 2007 Spike-timing-dependent plasticity of neocortical excitatory synapses on inhibitory interneurons depends on target cell type. J Neurosci 27, 97119720. [PubMed: 17804631]

Markram H, Toledo-Rodriguez M, Wang Y, Gupta A, Silberberg G, Wu C, 2004 Interneurons of the neocortical inhibitory system. Nat Rev Neurosci 5, 793-807. [PubMed: 15378039] 
McCall NM, Sprow GM, Delpire E, Thiele TE, Kash TL, Pleil KE, 2013 Effects of sex and deletion of neuropeptide $\mathrm{Y} 2$ receptors from GABAergic neurons on affective and alcohol drinking behaviors in mice. Front Integr Neurosci 7, 100. [PubMed: 24399943]

McCormick DA, Connors BW, Lighthall JW, Prince DA, 1985 Comparative electrophysiology of pyramidal and sparsely spiny stellate neurons of the neocortex. J Neurophysiol 54, 782-806. [PubMed: 2999347]

McGarry LM, Carter AG, 2016 Inhibitory Gating of Basolateral Amygdala Inputs to the Prefrontal Cortex. J Neurosci 36, 9391-9406. [PubMed: 27605614]

Medina KL, McQueeny T, Nagel BJ, Hanson KL, Schweinsburg AD, Tapert SF, 2008 Prefrontal cortex volumes in adolescents with alcohol use disorders: unique gender effects. Alcohol Clin Exp Res 32, 386-394. [PubMed: 18302722]

Melon LC, Nasman JT, John AS, Mbonu K, Maguire JL, 2018 Interneuronal delta-GABAA receptors regulate binge drinking and are necessary for the behavioral effects of early withdrawal. Neuropsychopharmacology.

Miyamae T, Chen K, Lewis DA, Gonzalez-Burgos G, 2017 Distinct Physiological Maturation of Parvalbumin-Positive Neuron Subtypes in Mouse Prefrontal Cortex. J Neurosci 37, 4883-4902. [PubMed: 28408413]

Murray AJ, Woloszynowska-Fraser MU, Ansel-Bollepalli L, Cole KL, Foggetti A, Crouch B, Riedel G, Wulff P, 2015 Parvalbumin-positive interneurons of the prefrontal cortex support working memory and cognitive flexibility. Sci Rep 5, 16778. [PubMed: 26608841]

Nigro MJ, Hashikawa-Yamasaki Y, Rudy B, 2018 Diversity and Connectivity of Layer 5 SomatostatinExpressing Interneurons in the Mouse Barrel Cortex. J Neurosci 38, 1622-1633. [PubMed: 29326172]

Nixon SJ, Tivis R, Parsons OA, 1995 Behavioral dysfunction and cognitive efficiency in male and female alcoholics. Alcohol Clin Exp Res 19, 577-581. [PubMed: 7573777]

Pava MJ, Woodward JJ, 2014 Chronic ethanol alters network activity and endocannabinoid signaling in the prefrontal cortex. Front Integr Neurosci 8, 58. [PubMed: 25100953]

Perez Y, Morin F, Lacaille JC, 2001 A hebbian form of long-term potentiation dependent on mGluR1a in hippocampal inhibitory interneurons. Proc Natl Acad Sci U S A 98, 9401-9406. [PubMed: 11447296]

Peterson BM, Mermelstein PG, Meisel RL, 2015 Estradiol mediates dendritic spine plasticity in the nucleus accumbens core through activation of mGluR5. Brain Struct Funct 220, 2415-2422. [PubMed: 24878822]

Pleil KE, Lowery-Gionta EG, Crowley NA, Li C, Marcinkiewcz CA, Rose JH, McCall NM, Maldonado-Devincci AM, Morrow AL, Jones SR, Kash TL, 2015 Effects of chronic ethanol exposure on neuronal function in the prefrontal cortex and extended amygdala. Neuropharmacology 99, 735-749. [PubMed: 26188147]

Priddy BM, Carmack SA, Thomas LC, Vendruscolo JC, Koob GF, Vendruscolo LF, 2017 Sex, strain, and estrous cycle influences on alcohol drinking in rats. Pharmacol Biochem Behav 152, 61-67. [PubMed: 27498303]

Radke AK, Jury NJ, Delpire E, Nakazawa K, Holmes A, 2017a Reduced ethanol drinking following selective cortical interneuron deletion of the GluN2B NMDA receptors subunit. Alcohol 58, 47 51. [PubMed: 28109345]

Radke AK, Jury NJ, Kocharian A, Marcinkiewcz CA, Lowery-Gionta EG, Pleil KE, McElligott ZA, McKlveen JM, Kash TL, Holmes A, 2017b Chronic EtOH effects on putative measures of compulsive behavior in mice. Addict Biol 22, 423-434. [PubMed: 26687341]

Ramirez DM, Kavalali ET, 2011 Differential regulation of spontaneous and evoked neurotransmitter release at central synapses. Curr Opin Neurobiol 21, 275-282. [PubMed: 21334193]

Randall CL, Roberts JS, Del Boca FK, Carroll KM, Connors GJ, Mattson ME, 1999 Telescoping of landmark events associated with drinking: a gender comparison. J Stud Alcohol 60, 252-260. [PubMed: 10091964]

Rodgers DA, Mc CG, 1962 Mouse strain differences in preference for various concentrations of alcohol. Q J Stud Alcohol 23, 26-33. [PubMed: 14493106] 
Rotaru DC, Yoshino H, Lewis DA, Ermentrout GB, Gonzalez-Burgos G, 2011 Glutamate receptor subtypes mediating synaptic activation of prefrontal cortex neurons: relevance for schizophrenia. $\mathbf{J}$ Neurosci 31, 142-156. [PubMed: 21209199]

Rozov A, Burnashev N, 1999 Polyamine-dependent facilitation of postsynaptic AMPA receptors counteracts paired-pulse depression. Nature 401, 594-598. [PubMed: 10524627]

Salling MC, Jane Skelly M, Avegno E, Regan S, Zeric T, Nichols E, Harrison NL, 2018 Alcohol consumption during adolescence in a mouse model of binge drinking alters the intrinsic excitability and function of the prefrontal cortex through a reduction in the hyperpolarizationactivated cation current. J Neurosci.

Sarihi A, Jiang B, Komaki A, Sohya K, Yanagawa Y, Tsumoto T, 2008 Metabotropic glutamate receptor type 5-dependent long-term potentiation of excitatory synapses on fast-spiking GABAergic neurons in mouse visual cortex. J Neurosci 28, 1224-1235. [PubMed: 18234900]

Seif T, Chang SJ, Simms JA, Gibb SL, Dadgar J, Chen BT, Harvey BK, Ron D, Messing RO, Bonci A, Hopf FW, 2013 Cortical activation of accumbens hyperpolarization-active NMDARs mediates aversion-resistant alcohol intake. Nat Neurosci 16, 1094-1100. [PubMed: 23817545]

Siciliano CA, Noamany H, Chang CJ, Brown AR, Chen X, Leible D, Lee JJ, Wang J, Vernon AN, Vander Weele CM, Kimchi EY, Heiman M, Tye KM, 2019 A cortical-brainstem circuit predicts and governs compulsive alcohol drinking. Science 366, 1008-1012. [PubMed: 31754002]

Sohal VS, Zhang F, Yizhar O, Deisseroth K, 2009 Parvalbumin neurons and gamma rhythms enhance cortical circuit performance. Nature 459, 698-702. [PubMed: 19396159]

Squeglia LM, Sorg SF, Schweinsburg AD, Wetherill RR, Pulido C, Tapert SF, 2012 Binge drinking differentially affects adolescent male and female brain morphometry. Psychopharmacology (Berl) 220, 529-539. [PubMed: 21952669]

Taniguchi H, He M, Wu P, Kim S, Paik R, Sugino K, Kvitsiani D, Fu Y, Lu J, Lin Y, Miyoshi G, Shima Y, Fishell G, Nelson SB, Huang ZJ, 2011 A resource of Cre driver lines for genetic targeting of GABAergic neurons in cerebral cortex. Neuron 71, 995-1013. [PubMed: 21943598]

Trantham-Davidson H, Burnett EJ, Gass JT, Lopez MF, Mulholland PJ, Centanni SW, Floresco SB, Chandler LJ, 2014 Chronic alcohol disrupts dopamine receptor activity and the cognitive function of the medial prefrontal cortex. J Neurosci 34, 3706-3718. [PubMed: 24599469]

Trantham-Davidson H, Centanni SW, Garr SC, New NN, Mulholland PJ, Gass JT, Glover EJ, Floresco SB, Crews FT, Krishnan HR, Pandey SC, Chandler LJ, 2017 Binge-Like Alcohol Exposure During Adolescence Disrupts Dopaminergic Neurotransmission in the Adult Prelimbic Cortex. Neuropsychopharmacology 42, 1024-1036. [PubMed: 27620551]

Tremblay R, Lee S, Rudy B, 2016 GABAergic Interneurons in the Neocortex: From Cellular Properties to Circuits. Neuron 91, 260-292. [PubMed: 27477017]

Urbano-Marquez A, Estruch R, Fernandez-Sola J, Nicolas JM, Pare JC, Rubin E, 1995 The greater risk of alcoholic cardiomyopathy and myopathy in women compared with men. JAMA 274, 149-154. [PubMed: 7596003]

Vargas WM, Bengston L, Gilpin NW, Whitcomb BW, Richardson HN, 2014 Alcohol binge drinking during adolescence or dependence during adulthood reduces prefrontal myelin in male rats. $\mathrm{J}$ Neurosci 34, 14777-14782. [PubMed: 25355229]

Varodayan FP, Sidhu H, Kreifeldt M, Roberto M, Contet C, 2018 Morphological and functional evidence of increased excitatory signaling in the prelimbic cortex during ethanol withdrawal. Neuropharmacology 133, 470-480. [PubMed: 29471053]

Woodward JJ, Pava MJ, 2009 Effects of ethanol on persistent activity and up-States in excitatory and inhibitory neurons in prefrontal cortex. Alcohol Clin Exp Res 33, 2134-2140. [PubMed: 19764936]

Zhong P, Yan Z, 2016 Distinct Physiological Effects of Dopamine D4 Receptors on Prefrontal Cortical Pyramidal Neurons and Fast-Spiking Interneurons. Cereb Cortex 26, 180-191. [PubMed: 25146372] 


\section{Highlights:}

- $\quad$ Parvalbumin interneurons (PV-INs) display properties of basket cells

- $\quad$ Somatostatin interneurons (SST-INs) display properties of Martinotti cells

- $\quad$ Female mice drink more than male mice given intermittent access (IA) ethanol

- IA ethanol differentially alters synaptic transmission onto PV-INs based on sex

- Excitatory drive onto SST-INs is depressed in all groups of mice after IA ethanol 
A
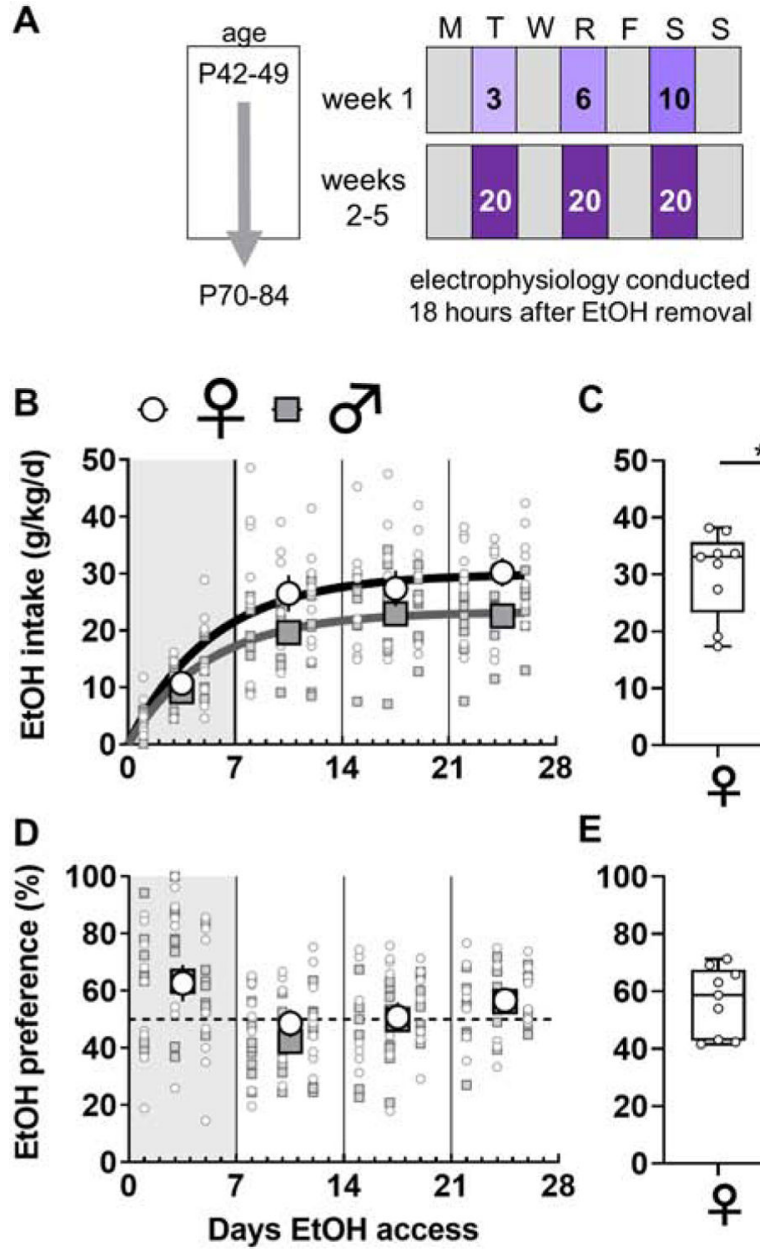

C

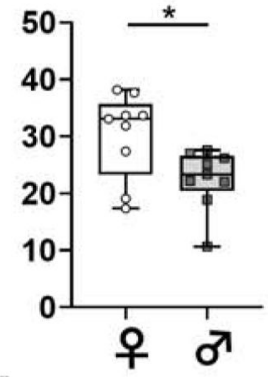

E

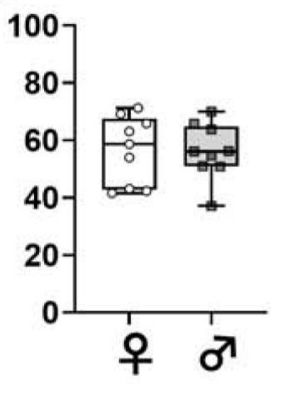

Figure 1. Sex differences in voluntary ethanol consumption under an intermittent access schedule.

(A) Beginning at 6-7 weeks of age, mice underwent 4 weeks of two-bottle choice, voluntary drinking. Ethanol was provided every other day on an intermittent access (IA) schedule. The ethanol concentration was ramped during the first week and set at $20 \%$ for the duration of the study. Animals were sacrificed for electrophysiology approximately 18 hours after ethanol was removed, at 10-12 weeks of age. (B) Female mice (light circles) displayed increased ethanol intake relative to male mice (dark squares) over the duration of the study (Least squares best-fit, one-phase association: 95\% confidence intervals of plateaus $\{27.1$ to $\left.33.6 \mathrm{~g} / \mathrm{kg} ; \mathrm{r}^{2}=0.46\right\}$ vs $\left\{21.5\right.$ to $\left.25.4 \mathrm{~g} / \mathrm{kg} ; \mathrm{r}^{2}=0.53\right\}$ ). $\mathrm{N}=9$ mice per group. (C) Female mice drank more during the last week of the IA ethanol paradigm $(30.2 \pm 2.5$ vs $22.6 \pm 1.7$ $\mathrm{g} / \mathrm{kg}$, *: $\mathrm{p}<0.05$, Mann-Whitney U test). (D-E) No sex difference in preference for ethanol over concurrently available water across the IA ethanol paradigm or during the last week of drinking. 
A
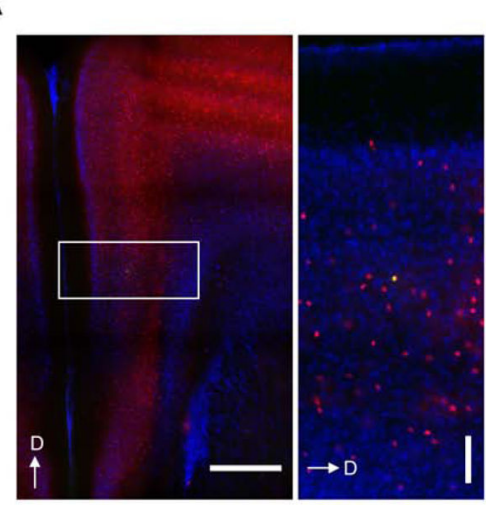

B

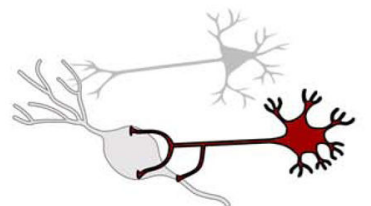

pyramidal

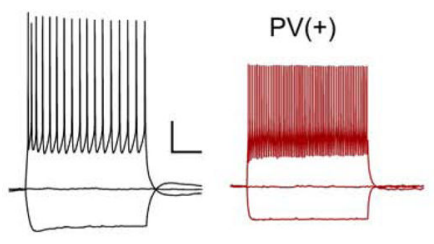

C

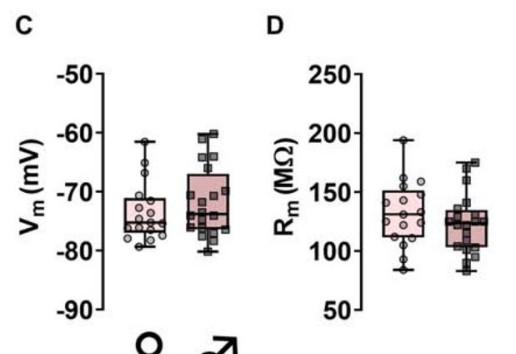

E

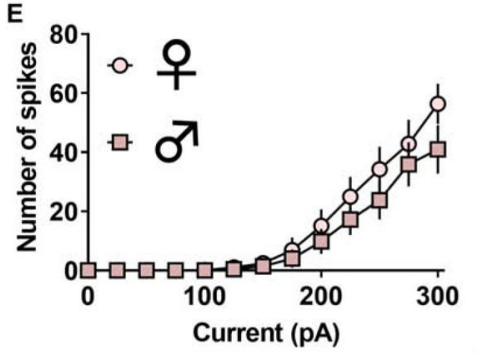

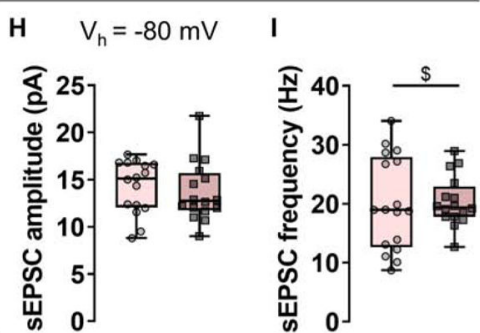

Figure 2. Parvalbumin (PV)-(+) neurons display functional characteristics of fast-spiking interneurons.

(A) Left, Representative image displaying TdTomato fluorescence (red) in PV-expressing neurons in the mouse prefrontal cortex (PFC). Right, boxed inset showing PV-IN distribution throughout layers of prelimbic PFC. PV-INs are highly expressed within layer 5 and rarely present within layer 1 of the mouse PFC. A representative PV-IN was infused with Alexa 488 dye (green). Scale bars indicate $500 \mu \mathrm{m}$ and $100 \mu \mathrm{m}$. D, dorsal. (B) Wholecell patch-clamp recordings were made from identified neurons in the PFC. Representative current-clamp recordings from an unlabeled pyramidal cell (left, black) and a TdTomatolabeled PV-IN (right, red). The pyramidal cell displays a hyperpolarization-activated sag and accommodating spike firing, physiological features that are minimal or absent in PV-INs. Scale bars indicate $20 \mathrm{mV}$ and $250 \mathrm{~ms}$. (C) Resting membrane potential $\left(\mathrm{V}_{\mathrm{m}}\right)$ in PV-INs from female mice (circles) and male mice (squares). $\mathrm{n} / \mathrm{N}=17 / 9,20 / 8$ cells/mice per group. (D) No difference in membrane resistance $\left(\mathrm{R}_{\mathrm{m}}\right)$ between PV-INs from female and male mice. $\mathrm{n} / \mathrm{N}=17 / 9,20 / 8$. (E) No difference in current-evoked spiking between PV-INs from female and male mice. $\mathrm{n} / \mathrm{N}=16 / 9,18 / 8$. (F) No difference in hyperpolarization sag ratio between PV-INs from female and male mice. $\mathrm{n} / \mathrm{N}=18 / 9,20 / 8$. (G) PV-INs from female mice display greater medium afterhyperpolarization (mAHP) than PV-INs from male mice $(2.71 \pm 0.30$ vs $1.72 \pm 0.22 \mathrm{mV}$, **: $\mathrm{p}<0.01$, Mann-Whitney $\mathrm{U}$ test). $\mathrm{n} / \mathrm{N}=18 / 9,20 / 8$. (H) 
After current-clamp recordings, cells were switch to voltage-clamp configuration and held at $-80 \mathrm{mV}$, the reversal potential for chloride. No difference in spontaneous excitatory postsynaptic current (sEPSC) amplitude between PV-INs from female and male mice. $\mathrm{n} / \mathrm{N}=$ 16/9, 16/7. (I) No difference in the mean of sEPSC frequency between PV-INs from female and male mice. A difference in the variance of sEPSC frequency was observed between female and male mice $\left(\mathrm{F}_{16,15}=3.526, \$: \mathrm{p}<0.01, \mathrm{~F}\right.$ test to compare variances $) . \mathrm{n} / \mathrm{N}=17 / 9$, $16 / 7$. 


\section{A}
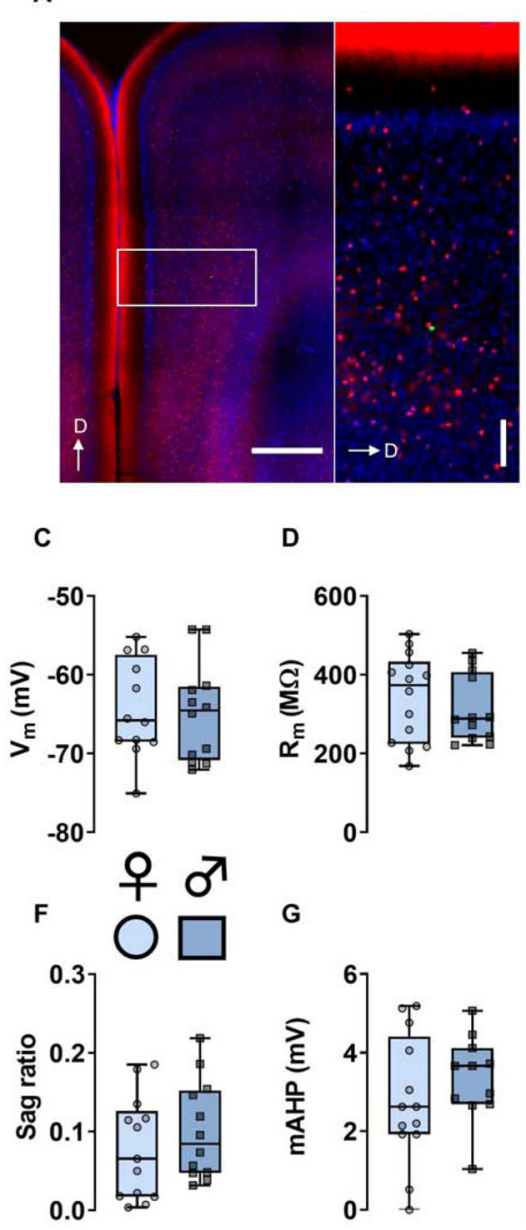

D

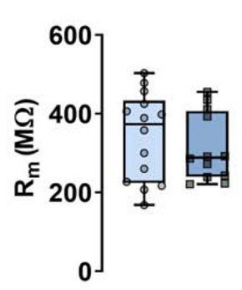

G

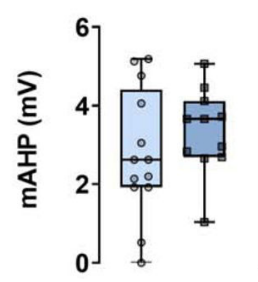

B

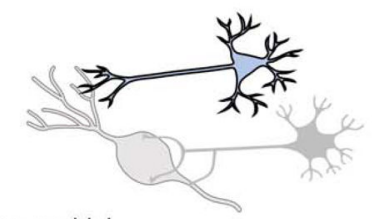

pyramidal

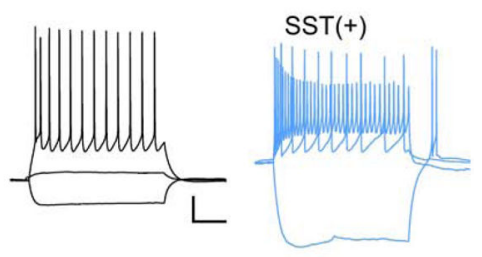

$E$
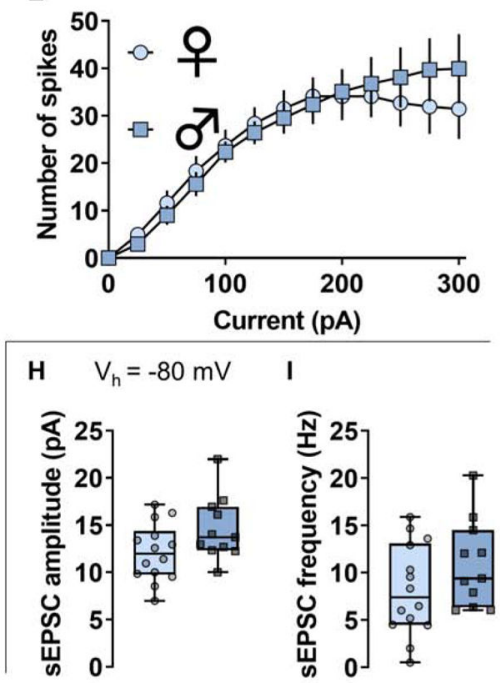

Figure 3. Somatostatin (SST)-(+) neurons display functional characteristics of Martinotti cells. (A) Left, Representative image displaying TdTomato fluorescence (red) in SST-expressing neurons in the mouse prefrontal cortex (PFC). Right, boxed inset showing SST-IN distribution throughout layers of prelimbic PFC. SST-INs are highly expressed throughout all cortical layers and densely innervate pyramidal cell dendrites within layer 1 . A representative SST-IN was infused with Alexa 488 dye (green). Scale bars indicate $500 \mu \mathrm{m}$ and $100 \mu \mathrm{m}$. D, dorsal. (B) Whole-cell patch-clamp recordings were made from identified neurons in the PFC. Representative current-clamp recordings from an unlabeled pyramidal cell (left, black) and a TdTomato-labeled SST-IN (right, blue). The pyramidal cell displays modest membrane resistance $\left(\mathrm{R}_{\mathrm{m}}\right)$ and does not fire during $25 \mathrm{pA}$ current injection current. In contrast, most SST-INs display high membrane resistance $\left(\mathrm{R}_{\mathrm{m}}\right)$ and fire action potentials in response to minimal current injection and hyperpolarization rebound. Scale bars indicate $20 \mathrm{mV}$ and $250 \mathrm{~ms}$. (C) Resting membrane potential $\left(\mathrm{V}_{\mathrm{m}}\right)$ in SST-INs from female mice (circles) and male mice (squares). $\mathrm{n} / \mathrm{N}=12 / 3$ cells/mice per group. (D) No difference in $\mathrm{R}_{\mathrm{m}}$ between SST-INs from female and male mice. $n / N=12 / 3,14 / 3$. (E) No difference in current-evoked spiking between SST-INs from female and male mice. $n / N=12 / 3$. (F) No difference in hyperpolarization sag ratio between SST-INs from female and male mice. $\mathrm{n} / \mathrm{N}$ $=13 / 3,12 / 3$. (G) No difference in medium afterhyperpolarization (mAHP) in SST-INs from 
female mice and male mice. $\mathrm{n} / \mathrm{N}=13 / 3$. (H) After current-clamp recordings, cells were switch to voltage-clamp configuration and held at $-80 \mathrm{mV}$, the reversal potential for chloride. No difference in spontaneous excitatory postsynaptic current (sEPSC) amplitude between SST-INs from female and male mice. $\mathrm{n} / \mathrm{N}=14 / 3,11 / 3$. (I) No difference in the mean of sEPSC frequency between SST-INs from female and male mice. $\mathrm{n} / \mathrm{N}=14 / 3,11 / 3$. 
A

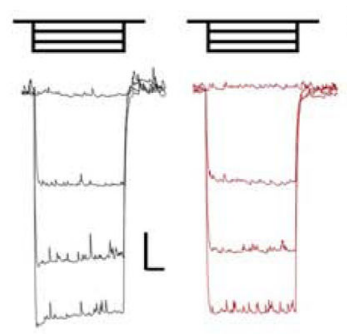

B

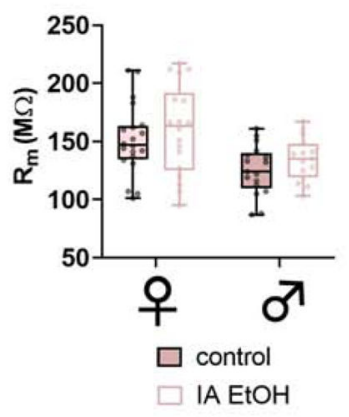

C

D
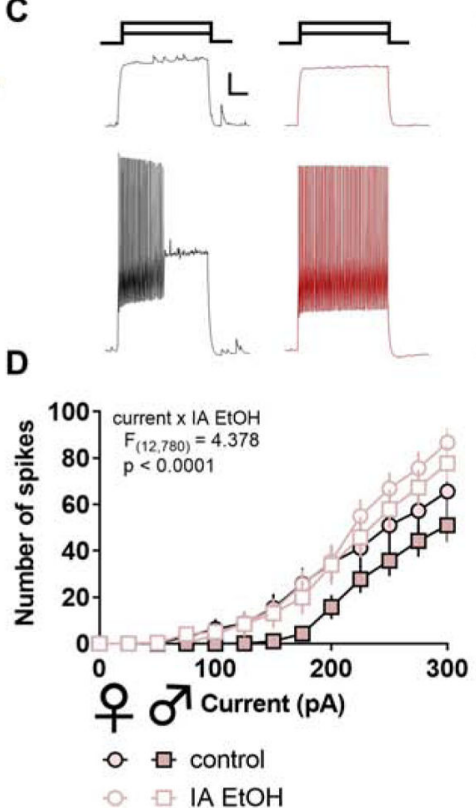

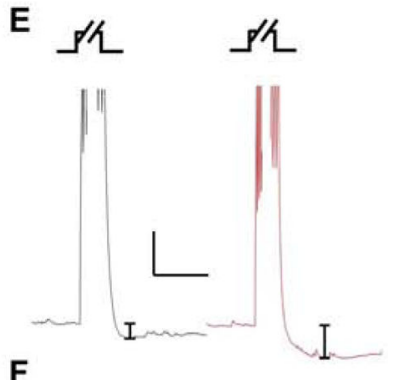

$\mathbf{F}$

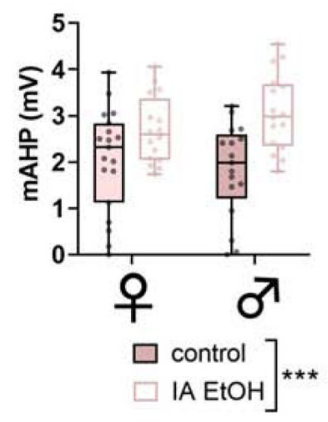

Figure 4. Intermittent ethanol increases excitability and medium afterhyperpolarization (mAHP) in parvalbumin interneurons (PV-IN) in mice.

(A) Representative responses to negative current injection steps $(-150,-100,-50,0 \mathrm{pA})$ in PV-INs from control and IA ethanol mice. Scale bars indicate $5 \mathrm{mV}, 200 \mathrm{~ms}$. (B) PV-INs from female mice displayed greater membrane resistance $\left(\mathrm{R}_{\mathrm{m}}\right)$ than PV-INs from male mice, although no main effect or interaction with IA ethanol exposure was observed (Two-way ANOVA main effect of sex: $\left.\mathrm{F}_{1,160}=13.78, \mathrm{p}<0.001\right)$. $\mathrm{n} / \mathrm{N}=16-19 / 5$ cells/mice per group. (C) Representative spike-firing in response to 100-pA (top) and 200-pA (bottom) injections in PV-INs from control (black) and IA ethanol (red) mice. Scale bars indicate $10 \mathrm{mV}, 200$ ms. (D) Increased spiking was observed in response to current injections in PV-INs from IA ethanol mice. (Three-way RM ANOVA current $x$ IA ethanol interaction: $F_{12,780}=4.378, p<$ 0.0001). $\mathrm{n} / \mathrm{N}=16-19 / 5$. (E) Representative mAHP in PV-INs from control and IA ethanol mice. mAHP was calculated as the decrease in membrane potential within 1-sec following sustained depolarization and spike-firing. Scale bars indicate $5 \mathrm{mV}, 250 \mathrm{~ms}$. (F) PV-INs from IA ethanol mice displayed enhanced mAHP relative to controls (Two-way ANOVA main effect of IA ethanol: $\left.\mathrm{F}_{1,64}=17.14, \mathrm{p}<0.001\right) . \mathrm{n} / \mathrm{N}=16-19 / 5$. 
A

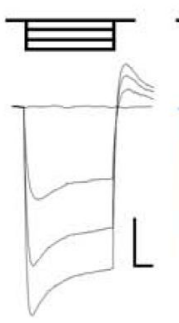

B

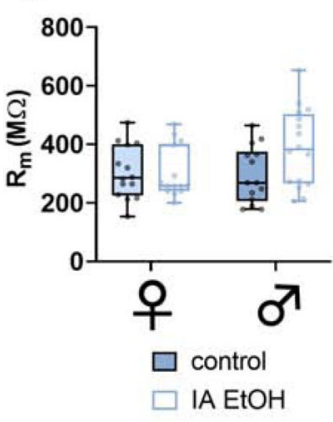

C
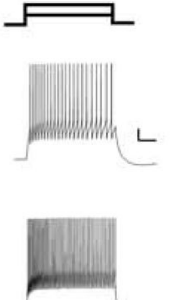

D

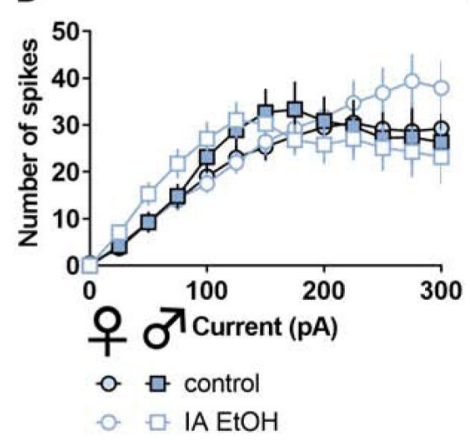

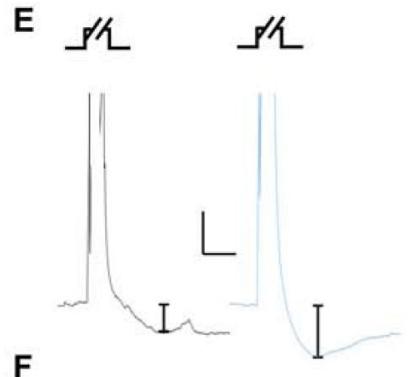

$\mathbf{F}$

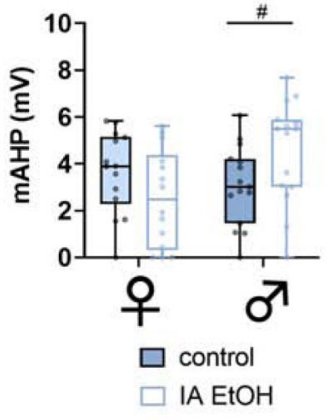

Figure 5. Intermittent ethanol increases medium afterhyperpolarization (mAHP) in somatostatin (SST-IN) interneurons in male mice.

(A) Representative responses to negative current injection steps $(-150,-100,-50,0 \mathrm{pA})$ in SST-INs from control and IA ethanol mice. Scale bars indicate $10 \mathrm{mV}, 200 \mathrm{~ms}$. (B) Minimal differences in SST-IN membrane resistance $\left(\mathrm{R}_{\mathrm{m}}\right)$ between control and IA ethanol mice (Two-way ANOVA sex x IA ethanol interaction: $\mathrm{F}_{1,54}=3.045, \mathrm{p}<0.09$ ). $\mathrm{n} / \mathrm{N}=14-16 / 4-5$ cells/mice per group. (C) Representative spike-firing in response to 100-pA (top) and 200pA (bottom) injections in SST-INs from control (black) and IA ethanol (blue) mice. Scale bars indicate $10 \mathrm{mV}, 200 \mathrm{~ms}$. (D) No differences in current-evoked spiking were observed related to IA ethanol in SST-INs (Three-way RM ANOVA). $\mathrm{n} / \mathrm{N}=15-16 / 4-5$. (E)

Representative mAHP in SST-INs from control and IA ethanol mice. mAHP was calculated as the decrease in membrane potential within 1-sec following sustained depolarization and spike-firing. Scale bars indicate $5 \mathrm{mV}, 250 \mathrm{~ms}$. (F) SST-INs from male IA ethanol mice displayed a trend towards enhanced mAHP relative to male controls (Two-way ANOVA sex $x$ IA ethanol interaction: $F_{1,54}=6.513, p<0.02$, \#: $\mathrm{p}<0.1$ Sidak post test). $\mathrm{n} / \mathrm{N}=14-16 / 4-5$. 
A

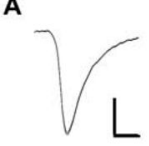

control

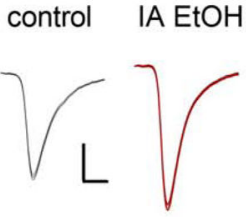

B
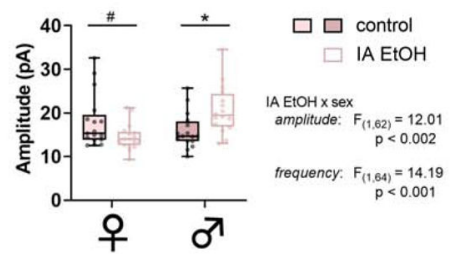

C

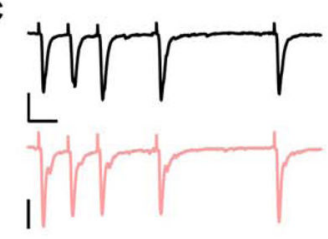

D

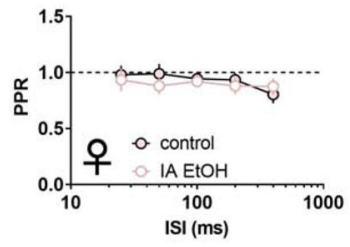

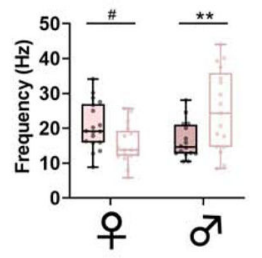
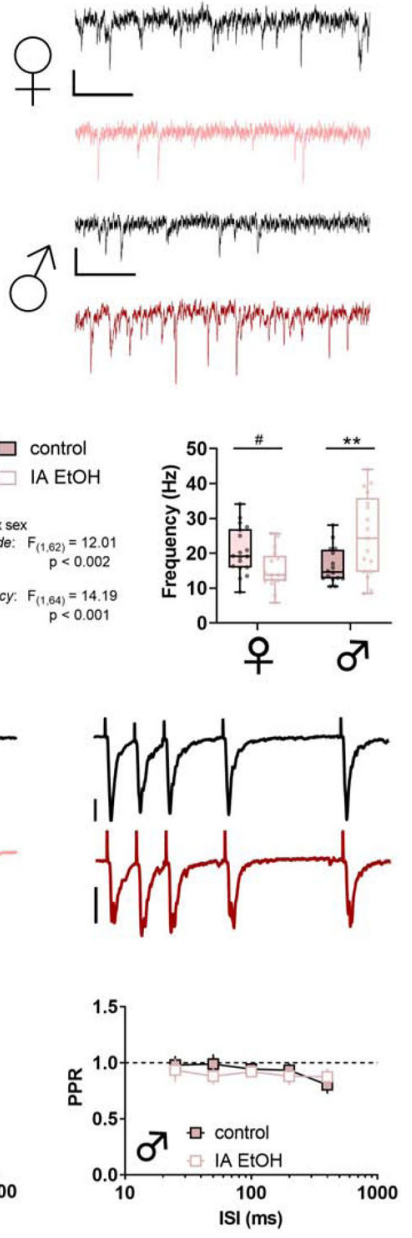

Figure 6. Intermittent access to ethanol generates diametrically opposing sex-dependent changes to excitatory synaptic strength onto parvalbumin-expressing interneurons (PV-INs).

(A) Left, Averaged sEPSC from representative experiment. Scale bars indicate $5 \mathrm{pA}, 2 \mathrm{~ms}$. Right, Representative spontaneous excitatory postsynaptic current (sEPSC) traces from PVINs from control (black) and IA ethanol (red) female mice. Scale bars indicate 10 pA, 100 ms. (B) Left, Decreased sEPSC amplitude in PV-INs from control and IA ethanol female mice (14.5 \pm 0.7 vs $17.9 \pm 1.5$ pA, \#: $\mathrm{p}<0.09$, Sidak post test). In contrast, greater sEPSC amplitude was observed in PV-INs from IA ethanol group relative to control male mice (20.7 \pm 1.4 vs $15.9 \pm 1.0$ pA, *: $\mathrm{p}<0.05$, Sidak post test). $\mathrm{n} / \mathrm{N}=16-17 / 5$ cells/mice per group. Right, PV-INs from female mice given IA ethanol exhibited decreased sEPSC frequency relative to controls (15.2 \pm 1.3 vs $21.2 \pm 1.6 \mathrm{~Hz}$, \#: $\mathrm{p}<0.09$, Sidak post test), while PV-INs from male mice given IA ethanol displayed increased sEPSC frequency relative to controls $(25.1 \pm 2.8$ vs $16.5 \pm 1.3 \mathrm{~Hz}, * *: \mathrm{p}<0.01$, Sidak post test $) . \mathrm{n} / \mathrm{N}=16-19 / 5$. (C)

Representative recordings from paired-pulse ratio (PPR) experiments. Scale bars indicate 50 pA, 25 ms. (D) No group difference in paired-pulse ratio (PPR) between control and IA ethanol female mice (Left) or male mice (Right) across several interstimulus intervals (ISIs) (Three-way repeated-measures ANOVA). n/N = 7-9/3. 
A

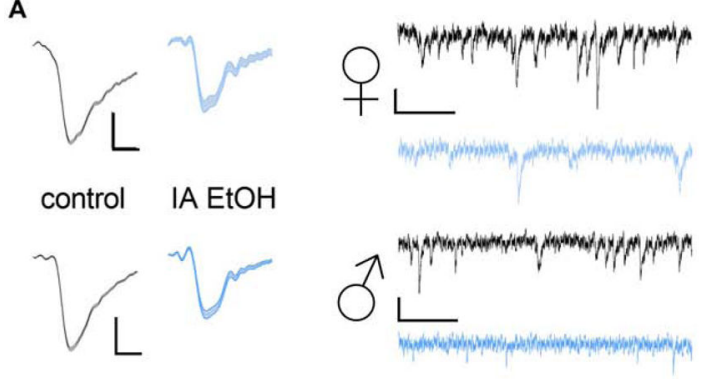

B

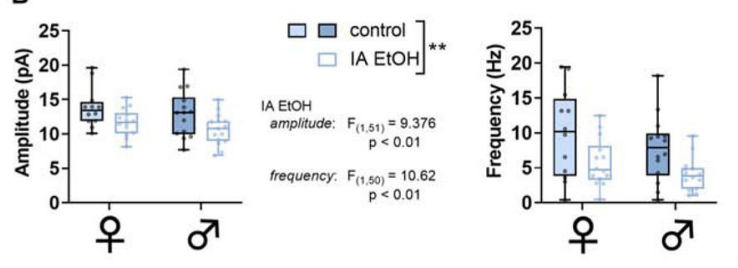

c
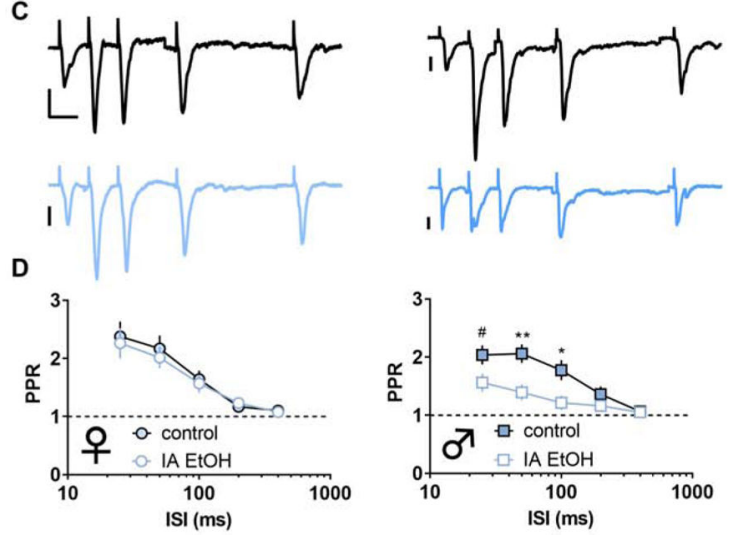

Figure 7. Intermittent access to ethanol (IA ethanol) decreases excitatory synaptic strength onto somatostatin interneurons (SST-INs).

(A) Left, Averaged sEPSC from representative experiment. Scale bars indicate $5 \mathrm{pA}, 2 \mathrm{~ms}$. Right, Representative spontaneous excitatory postsynaptic current (sEPSC) traces from SSTINs from control (black) and IA ethanol (blue) female mice. Scale bars indicate $10 \mathrm{pA}, 100$ ms. (B) Decreased sEPSC amplitude was observed in SST-INs from IA ethanol mice relative to controls. (Two-way ANOVA, main effect of IA ethanol). $\mathrm{n} / \mathrm{N}=12-17 / 4-5$ cells/mice per group. Right, SST-INs from mice given IA ethanol displayed decreased sEPSC frequency relative to controls. (Two-way ANOVA, main effect of IA ethanol). $\mathrm{n} / \mathrm{N}=12-17 / 4-5$. (C) Representative recordings from paired-pulse ratio (PPR) experiments. Scale bars indicate 20 pA, 25 ms. (D) Sex difference in PPR following IA ethanol (Three-way repeated-measures ANOVA, sex x ISI interaction: $F_{4,156}=5.736, p<0.001$; IA ethanol x ISI interaction: $F_{4,156}$ $=2.804, \mathrm{p}<0.03)$. Left, No group difference in paired-pulse ratio (PPR) between control and IA ethanol female mice across multiple interstimulus intervals (ISI). $\mathrm{n} / \mathrm{N}=7-9 / 3$, Right, Decreased PPR in SST-INs from male mice with access to IA ethanol (Two-way RM ANOVA, ISI $x$ IA ethanol interaction: $F_{4,84}=4.6, p<0.003$; main effect of ISI: $F_{4,84}=$ 24.85, $\mathrm{p}<0.0001$; main effect of IA ethanol: $\mathrm{F}_{1,21}=6.897, \mathrm{p}<0.02$; $: \mathrm{p}<0.1, * \mathrm{p}<0.05$, **: $\mathrm{p}<0.01$, Sidak post test) $\mathrm{n} / \mathrm{N}=11-12 / 4$.

Neuropharmacology. Author manuscript; available in PMC 2021 November 01. 